\title{
Technological Evaluation of Cellulose Carbamate Synthesized from Rice Straw and its Utilization as Dye Adsorbent
}

\author{
I. Abd El-Thalouth, H. M. El-Hennawi", S. Tawfik ${ }^{*}$, Sh. Abd \\ El-Salam* and E. Adel* \\ Textile Research Division, Dyeing, Printing and Textile \\ Auxilaries Department, National Research Centre(Scopus \\ affliation ID60014618), El-Behouth St. (former El-Tahrir str.), \\ Dokki, P.O. 12622, Giza and *Faculty of Applied Arts, Helwan \\ University, Cairo, Egypt.
}

\begin{abstract}
1. GYPTIAN rice straw was subjected to pulping via alkali C scouring followed by hypochloric bleaching. The obtained cellulosic pulp was allowed to react with two different amounts of urea at high temperature to obtain cellulose carbamate acquire nitrogen content of 0.13 and 0.16 on using 10 and $20 \mathrm{~g}$ urea/100g cellulose, pulp, respectively. The obtained carbamate derivatives were evaluated as dye adsorbent for different reactive dyes.

Different factors were investigated as the nature of colour used, the technique applied, the time of treatment, and concentration of dyes used. It wa $\mathrm{s}$ found that the magnitude of the adsorbed colour depends on the $\mathrm{N} \%$, whereas the $\% \mathrm{~N}$ increases the $\%$ colour removal increases too. As the concentration of the dye increases from 0.01 to $0.5 \mathrm{~g} /$ $1000 \mathrm{ml}$, the colour removal \% decreases regularly. It is clear from the obtained results that the \% colour removal as well as the time to reach the maximum colour removal percent depend on: a) the nature of the reactive dye used, (b) the degree of carbamation expressed as $\% \mathrm{~N}$ and (c) the technique applied.
\end{abstract}

Keywords: Rice straw, Colour removal, Ultrasonic, adsorption and carbamation.

About one million acres of rice crops were grown in Egypt. One acre of rice produces two tons of straw which means that over two million tons of straw waste was left behind after the harvest in October and November for burning. The burning of rice straw emits $\mathrm{CO}$ gas and particulates, by products found to have a significant effect on the quality of air and people's health. Rice burning has been linked to the formation of similar black clouds around the world ${ }^{(1,2)}$.

Textile industries are among the most polluting industries in terms of the volume and the complexity of treatment of its effluents discharge. Most commercially used dyes are resistant to biodegradation, thus, these dyes can significantly affect

\#Corresponding author: Heba El-Hennawi

E-mail: skybird740@yahoo.com 
photosynthetic activity in aquatic life due to reduced light penetration and may also be toxic to certain forms of aquatic life ${ }^{(3)}$. Different treatment methods have been used for treatment, including filtration, flocculation, chemical precipitation, ion exchange, membrane separation, and adsorption ${ }^{(4)}$.The adsorption process provides an attractive alternative treatment, especially if the adsorbent is low cost and readily available. The other advantage of adsorption process is absence of toxic harmful substances ${ }^{(5)}$. Activated carbon is the most widely used adsorbent, but it is expensive and at its regeneration process is high cost ${ }^{(6)}$. Therefore, research is on to look for new adsorbent materials with low - cost, abundant and eco-friendly ${ }^{(7)}$. A number of non-conventional low cost adsorbent used for dye removal as modified clays ${ }^{(8)}$, natural Iraqi clay ${ }^{(9)}$ wood, waste orange peel, banana pith, maze cobs, barley husk, bagasse pith, ... etc ${ }^{(10-13)}$. In our previous work we have investigated the ability to use native, alkali treated or cellulose pulp of rice straw as dye adsorbent $^{(14)}$.

In this study, different carbamate cellulose derivatives derived from rice straw pulp was synthesized, and evaluated as adsorbent for different dyestuffs to minimize pollution from their effluent.

\section{Experimental}

\section{Materials and reagents}

Native rice straw supplied by Racta Co. for Paper Manufacture, Alexandria, Egypt was used. The following different dyes (Scheme 1) selected from the most dyestuffs which are used from the Egyptian Textile Industries:

$>$ Sunzol Brilliant Violet 5 R (C. I. Reactive Violet 5)

$>$ Sunzole Blue 19 (C. I. Reactive Blue 19)

$>$ Ginacryl Malachite Green M (C. I. Basic. Green 4)

$>$ Ginacryl G. yellow GLE 200\% (C. I. Basic yellow 28)

$>$ Dystar. Green BW (C. I. Acid Green 27)

$>$ Dystar. Supralan Blue 2 R (C. I. Acid blue 225)

Sodium hydroxide, Sodium hypochlorite and urea all of laboratory grade chemicals were also used.

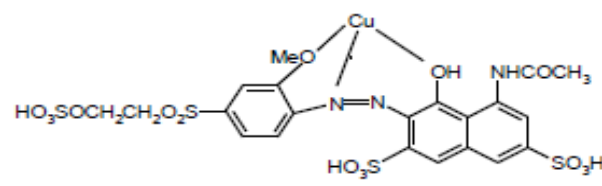

Reactive Violet 5

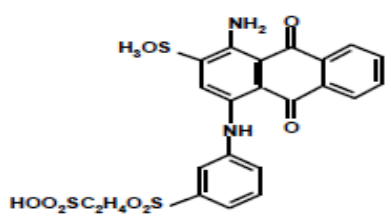

Reactive Blue 19

Egypt. J. Chem. 59, No. 1 (2016) 


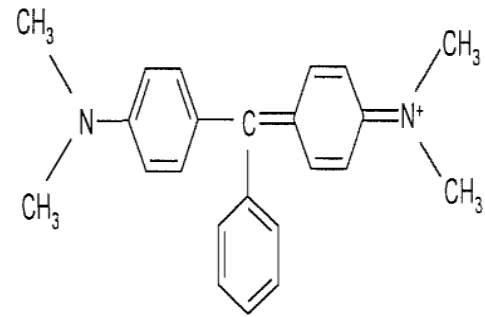

Basic Green 4

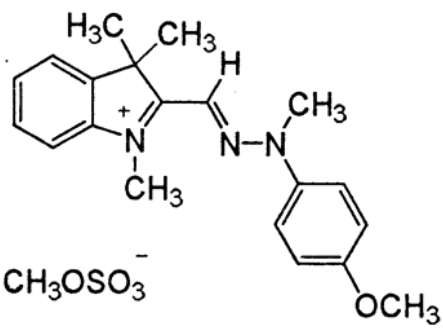

Basic Yellow 28

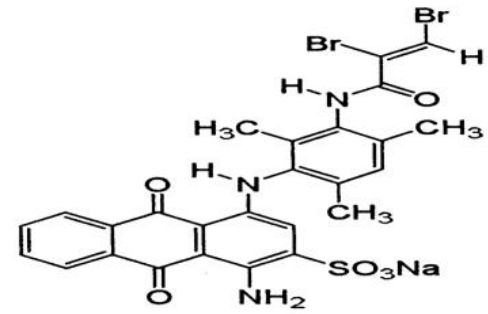

Acid blue 225

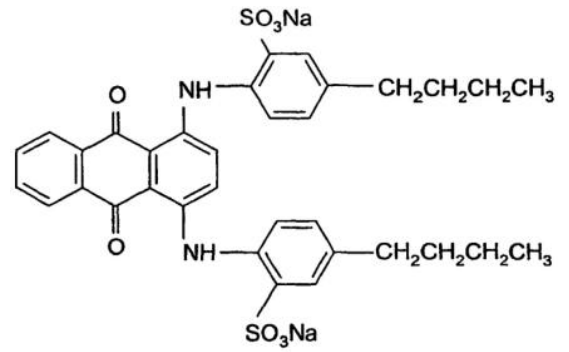

Acid Green 27

Scheme 1. Chemical structure of dyes.

Egypt. J. Chem. 59 No. 1 (2016) 
Apparatus

Ultrasonic cleaner model SH200-6L, power (w) 200 and power supply:220v/50Hz.its made in USA.

\section{Methods}

Preparation of bleached sample

Rice straw was cut to strips ( $2 \mathrm{~cm}$ length) and treated with $4 \%$ sodium hydroxide solution, maintaining liquor ratio at $5: 1$ for $2 \mathrm{hr}$ in a stationary autoclave at $120^{\circ} \mathrm{C}$. The sample was left to cool, washed thoroughly with running water till free from alkali, and finally air dried at ambient conditions. The alkali-treated sample was subjected to sodium hypochlorite $(\mathrm{NaOCl})$ bleaching $(4 \mathrm{~g} / \mathrm{l}$ activechlorine) for $2 \mathrm{hr}$ at room temperature, keeping liquor ratio at 10:1, followed by washing thoroughly with running water and finally air drying ${ }^{(14)}$

\section{Preparation of cellulose carbamate derivatives}

The prepared rice straw pulp was subjected to carbamation using two different amounts of urea according to the following technique:

The dry bleached rice straw was grinded mechanically in presence of urea at ratio of 1:10 urea: cellulose $(\mathrm{w} / \mathrm{w})$ in the solid state. The grinded sample was subjected to thermal treatment at $165^{\circ} \mathrm{C}$ for $30 \mathrm{~min}$.

The prepared carbamated sample was purified from the remains of urea via extraction in soxhlet till free from salts and finally air dried. Another sample was also prepared by the same technique using a ratio of 1:20 urea: cellulose.

\section{Measurements and analysis}

Procedure of dye adsorption

Different amounts of the prepared two carbamate cellulose were added separately to aqueous solutions of the selected dyes $(0.01 \mathrm{~g} / \mathrm{l})$ dissolved in $1000 \mathrm{ml}$ of distilled water.

The suspension was treated using either mechanical shaking or ultrasonic technique for different periods of time and temperatures. At the end, aliquot was centrifuged at $5000 \mathrm{rpm}$ for $30 \mathrm{~min}$ and the dye concentration in the clear solution was evaluated colourimetrically at the maximum wavelength for every dyestuff. The absorbance was measured using a double-beam spectrophotometer (Thermo Electron Corporation Unican 300, England). The percent dye absorption was calculated using the following equation ${ }^{(15)}$ :

$$
\% \text { dye adsorption }=\frac{\text { colour adsorption for the origin }- \text { colour adsorption for the treated sample }}{\text { colour adsorption for the origin }} \times 100
$$

\section{Analysis and measurements}

Determination of nitrogen content

Nitrogen content of the treated fabric was determined according to Kjeldahl method $^{(16)}$ 


\section{Results and Discussion}

The main aim of the present work was to prepare cabamate derivatives and evaluate them as dye adsorbent. Hence cellulose pulp was prepared from rice straw and subjected to react with different amounts of urea. The prepared derivatives were analysed for N\% content and the results are cited in TABLE 1.

TABLE 1. N\% content of carbamate derived from rice straw.

\begin{tabular}{|c|c|}
\hline Substrate & N\% \\
\hline Amount of urea $10 \mathrm{~g} / 100 \mathrm{~g}$ & 0.13 \\
\hline Amount of urea $20 \mathrm{~g} / 100 \mathrm{~g}$ & 0.16 \\
\hline
\end{tabular}

Effect of concentration of partially carbamate cellulose derived from rice straw as dye adsorbents

The prepared two different carbamate derivatives were used as adsorbent for reactive dyes using two different techniques, i.e. mechanical shaking and ultrasonic. Figure 1 and 2 represent the data obtained on using different amounts of the adsorbent.

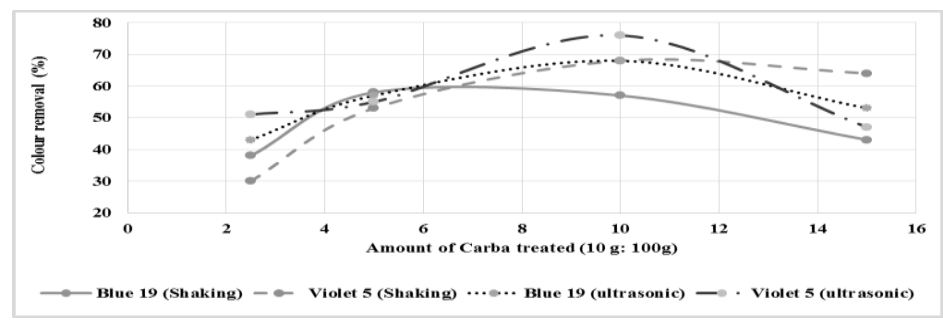

Violet 5: Time: 45 min., Temp: $30^{\circ} \mathrm{C}$

Blue 19: Time: 45 min., Temp: $30^{\circ} \mathrm{C}$

Fig. 1. Effect of the amount of carbamate derived from rice straw of $\% \mathrm{~N} 0.13$ on the colour removal \% using shaking and ultrasonic.

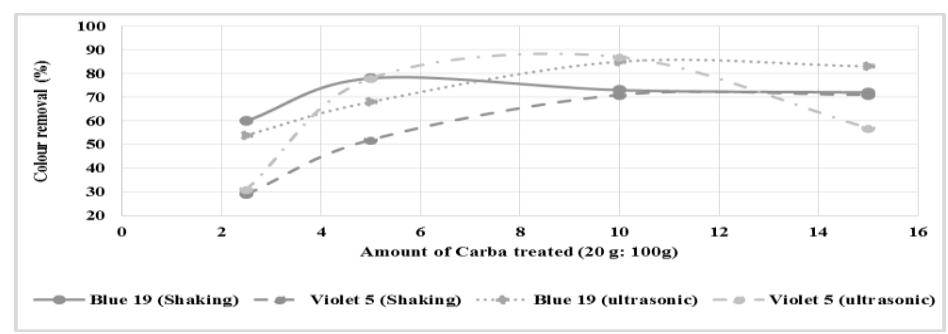

Violet 5: Time: 45 min., Temp: $30^{\circ} \mathrm{C}$

Blue19: Time: 45 min., Temp: $30^{\circ} \mathrm{C}$

Fig. 2. Effect of the amount of carbamate derived from rice straw of $\% \mathrm{~N} 0.16$ on the percent colour removal on using shaking. 
It is clear from the data that increasing the amount of carbamate derivatives is accompanied by an increase in the \% colour removal to reach the maximum value. The latter was arrived on using $5 \mathrm{~g}$ adsorbent $/ 100 \mathrm{~g}$ dye solution in case of reactive blue19 which conducted via using mechanical shaking, or $10 \mathrm{~g}$ on using ultrasonic technique.

While on using reactive violet 5 the maximum dye adsorption was attained on using $10 \mathrm{~g}$ adsorbent, irrespective of the technique applied.

However, in most cases increasing the carbamate groups expressed as $\% \mathrm{~N}$ on the cellulose chains is accompanied by an increase in \% colour removal. For example in case of reactive blue19 for the sample conducted using ultrasonic, the maximum \% colour removal was obtained at using $10 \mathrm{~g}$ and found to be 86.1 and $75.5 \%$ for the samples prepared using $20,10 \mathrm{~g}$ urea/ $100 \mathrm{~g}$ cellulose respectively, i.e. which contain greater amounts of carbamate groups.

It is obvious from the data that introduction of $\left(-\mathrm{CONH}_{2}\right)$ groups on the cellulose molecules increases its capacity to absorb the reactive dye. Where, in case of reactive violet5 on using $10 \mathrm{~g}$ of the substrate for the samples conducted via mechanical shaking the \% colour removal was found to be $45.71,67.31$ and $71 \%$ on using cellulose pulp, carbamate derivative of $\% \mathrm{~N}$ and carbamate derivative of $0.16 \% \mathrm{~N}$, respectively.

The improvement of the capacity of the cellulose towards colour adsorption may be due to the open structure of cellulose attained by the introduction of (Cellulose-O-CONH${ }_{2}$ ) group.

\section{Effect of treatment time}

Figures 3 and 4 represent the data obtained on studying the shaking time of the two different carbamate derivatives on using either mechanical shaking or ultrasonic technique for the mentioned two reactive dyes.

It is clear from the data that the \% colour removal as well as the time to reach the maximum colour removal depends on: (a) the nature of the reactive dye used, (b) the degree of carbamation expressed as $\% \mathrm{~N}$ and (c) the technique applied, i.e. either mechanical shaking or ultrasonic technique.

In case of using reactive violet 5 for the sample acquire the relatively $\% \mathrm{~N}$ the maximum dye adsorption was achieved after $15 \mathrm{~min}$ on using ultrasonic technique and after $30 \mathrm{~min}$ on using mechanical shaking. While for the sample which acquire the relatively higher $\% \mathrm{~N}$ the maximum dye adsorption was achieved after 30min and 45 min on using mechanical shaking and ultrasonic technique, respectively. 
While on using reactive blue 19 the maximum dye adsorption was attained after 30 and $45 \mathrm{~min}$ on using carbamate derivative acquire relatively low and high $\% \mathrm{~N}$, respectively irrespective of the technique applied for shaking.

It is also obvious from the data that on using carbamate derivative of low $\% \mathrm{~N}$ the magnitude of the percent colour removal was 81.5 and $67.8 \%$ on using reactive violet5 and 75.5 and $58.8 \%$ on using reactive blue19 for the sample acquire the relatively higher $\% \mathrm{~N}$ it was 86.1 and $77.7 \%$ on using reactive blue 19 on using either ultrasonic or mechanical shaking, respectively.

It can be concluded that in all cases, i.e. irrespective of the nature of colour used or the technique applied, the magnitude of the adsorbed colour depends on the $\% \mathrm{~N}$. as the $\% \mathrm{~N}$ increases the $\%$ colour removal increases too. This is expected since amino group acquire positive charge and the reactive dye acquires negative charge. As the amount of amino groups increases the capacity of the adsorbent increases.

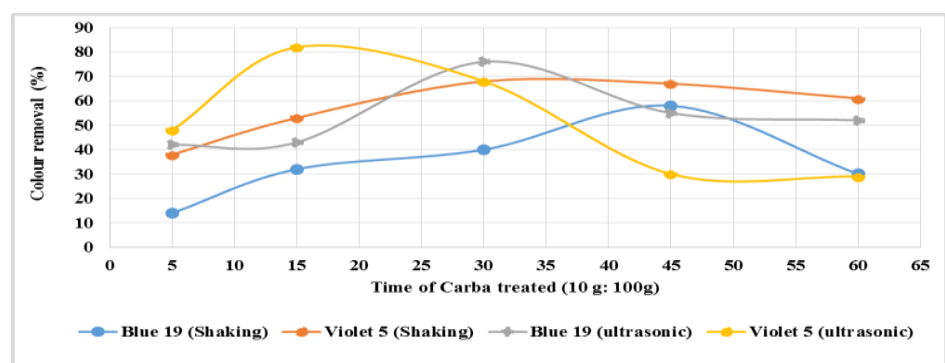

Violet5: $10 \mathrm{~g}: 100 \mathrm{ml}$, Temp.: $30^{\circ} \mathrm{C}$

Blue19: 5g: $100 \mathrm{ml}$, Temp.: $30^{\circ} \mathrm{C}$

Fig. 3. Effect of treatment time on using carbamate derivative acquire $\% \mathrm{~N} 0.13 \mathrm{gm}$ on the colour removal \% on using different reactive dyes (using shaking and ultrasonic).

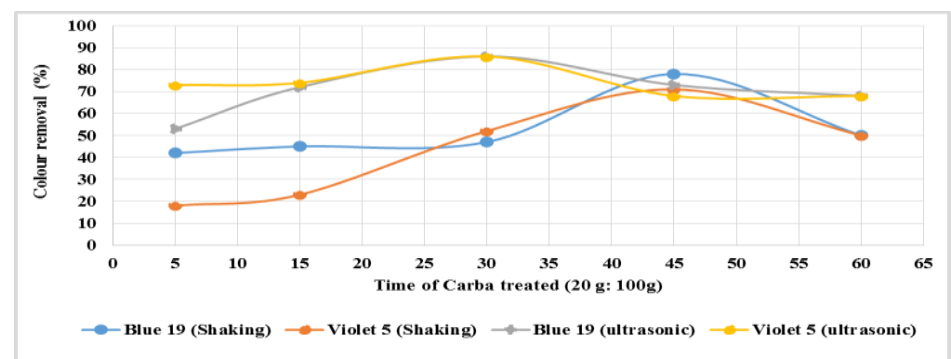

Violet5: $10 \mathrm{~g}: 100 \mathrm{ml}$, Temp.: $30^{\circ} \mathrm{C}$

Blue19: 5g: 100ml, Temp.: $30^{\circ} \mathrm{C}$

Fig. 4. Effect of treatment time on using carbamate derivative acquire $\% \mathrm{~N} 0.16 \mathrm{gm}$ on the colour removal \% on using different reactive dyes (using shaking and ultrasonic). 


\section{Effect of dye concentration}

Figures 5 and 6 represent the data obtained on investigation of the effect of dye concentration on the $\%$ dye removal from its solution on using either mechanical stirring or ultrasonic technique.

It is clear from the data, that as the concentration of the dye increases from 0.01 to $0.5 \mathrm{~g} / 100 \mathrm{ml}$, the $\%$ colour removal decreases regularly. The same trend was also observed on using the original, alkali treated, cellulosic pulp or carboxymethyl derivatives of rice straw and can be explained on the same basis, as previously mentioned, as the concentration of the dye increases the rate of dye aggregation increases and its mobility decreases hence the adsorbed dye decreases.

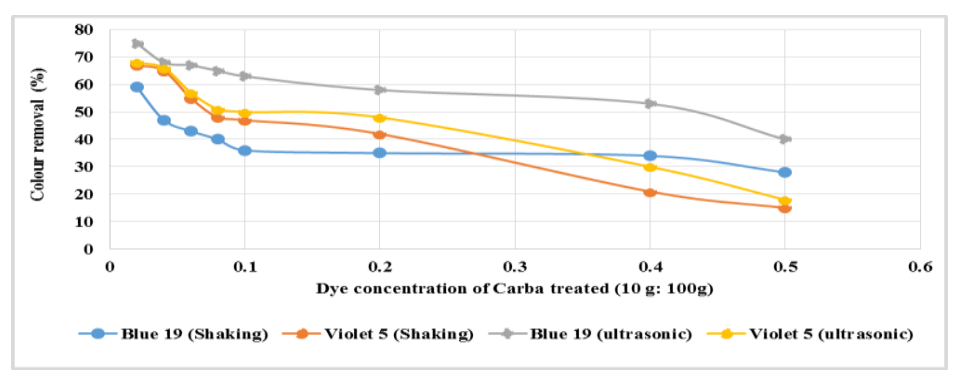

Violet5: $10 \mathrm{~g}: 100 \mathrm{ml}$, Temp $: 30^{\circ} \mathrm{C}$, Time:30min.

Blue19:5g:100ml,Temp.:30 ${ }^{\circ} \mathrm{C}$,Time: $45 \mathrm{~min}$.

Fig. 5. Effect of dye concentration on using carbamate derivative acquire $\% \mathrm{~N} 0.13$ on the percent colour removal on using different reactive dyes (using shaking and ultrasonic).

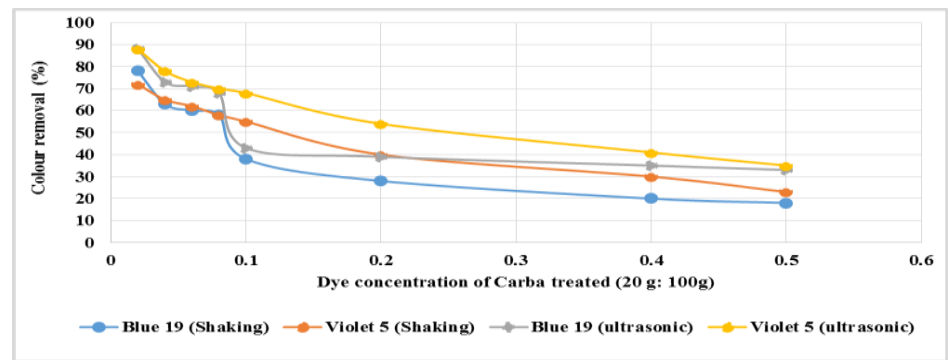

Violet5: 10g: 100ml, Temp.: $30^{\circ} \mathrm{C}$, Time: $30 \mathrm{~min}$. Blue19: $5 \mathrm{~g}: 100 \mathrm{ml}$, Temp.: $30^{\circ} \mathrm{C}$, Time: $45 \mathrm{~min}$.

Fig. 6. Effect of dye concentration on using carbamate derivative acquire $\% \mathrm{~N} 0.16$ on the percent colour removal on using different reactive dyes (using shaking and ultrasonic).

\section{Effect of nature of the dyestuff used}

Finally, it is worthy to investigate the effect of nature of the dyestuff used on the percent colour removal by using cellulose carbamate derivatives $(0.13$ or 
0.16). To achieve these four different dyestuffs (two of them acid and the other basic dyestuffs) were chosen and used with the aforementioned carbamate derivatives under identical conditions on using either mechanical stirring or ultrasonic technique. Table 2 represents the results obtained on using either mechanical stirring or ultrasonic technique, respectively.

Generally speaking it is clear from the data that, irrespective of the nature of dyestuff used or the adsorbent, the \% colour removal is higher for all the samples conducted via ultrasonic technique compared with those conducted via shaking. Furthermore, it is clear from the data that the percent colour removal on using acid dyes is relatively higher than their corresponding samples conducted using basic dyes. This phenomenon holds true regardless of the nature of the adsorbent used. However, as the degree of carbamation increases (i.e. the $\% \mathrm{~N}$ increases) the magnitude of the \% colour removal in case of acid dyestuffs increases too.

The increase in the \% colour removal on using acid dyestuffs is expected since acid dyes acquire negative charges and carbamate groups acquire positive charges, while basic dyes acquire positive charges. Hence the $\%$ colour removal on using acid dyestuffs is higher than using basic dyestuffs. As the $\% \mathrm{~N}$ increases the number of the positive charges on the polymer increases and hence its capacity to attract or repel the dyestuff molecules increases.

TABLE 2. Effect of nature of dyestuff on the ability of carbamate derivatives towards colour removal (using shaking and ultrasonic).

\begin{tabular}{|c|c|c|c|c|c|c|c|c|c|}
\hline \multirow{2}{*}{\multicolumn{2}{|c|}{ Substrate }} & \multicolumn{2}{|c|}{ Acid blue 225} & \multicolumn{2}{|c|}{ Acid green 27} & \multicolumn{2}{|c|}{ Basic green 4} & \multicolumn{2}{|c|}{ Basic yellow 28} \\
\hline & & \multirow{2}{*}{$\begin{array}{c}\text { Abs } \\
0.038\end{array}$} & \multirow{2}{*}{$\begin{array}{c}\begin{array}{c}\% \\
\text { Colour } \\
\text { removal }\end{array} \\
62 \% \\
\end{array}$} & \multirow{2}{*}{$\begin{array}{c}\text { Abs } \\
0.040\end{array}$} & \multirow{2}{*}{ 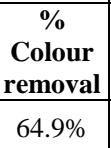 } & \multirow{2}{*}{$\begin{array}{c}\text { Abs } \\
0.090\end{array}$} & \multirow{2}{*}{$\begin{array}{c}\begin{array}{c}\% \\
\text { Colour } \\
\text { removal }\end{array} \\
36.6 \% \\
\end{array}$} & \multirow{2}{*}{\begin{tabular}{c|} 
Abs \\
0.099
\end{tabular}} & \multirow{2}{*}{$\begin{array}{c}\begin{array}{c}\% \\
\text { Colour } \\
\text { removal }\end{array} \\
57.6 \% \\
\end{array}$} \\
\hline Carbamated & shaking & & & & & & & & \\
\hline (D.S.10gm) & ultrasonic & 0.030 & $70 \%$ & 0.038 & $73.2 \%$ & 0.081 & $42.9 \%$ & 0.090 & $61.5 \%$ \\
\hline \multirow{2}{*}{$\begin{array}{l}\text { Carbamated } \\
\text { derivative } \\
\text { (D.S.20gm) }\end{array}$} & shaking & 0.022 & $78 \%$ & 0.033 & $71.0 \%$ & 0.110 & $22.5 \%$ & 0.093 & $60.2 \%$ \\
\hline & ultrasonic & 0.019 & $81 \%$ & 0.030 & $78.8 \%$ & 0.095 & $33.0 \%$ & 0.088 & $62.3 \%$ \\
\hline
\end{tabular}

\section{Conclusion}

In most cases increasing the carbamate groups expressed $\% \mathrm{~N}$ on the cellulose chains is accompanied by an increase in \% colour removal. For example in case of reactive blue19 for the sample conducted using ultrasonic, the maximum \% colour removal was found to be $86.1 \%$ and $75.5 \%$ for the samples prepared using 20 or $10 \mathrm{~g}$ urea/100g ( $\mathrm{N} \% 0.16$ and 0.13 ) cellulose respectively; i.e. which contain greater amounts of carbamate group.

It is clear from the obtained results that the $\%$ colour removal as well as the time to reach the maximum colour removal depend on: (a) the nature of dyes 
used, (b) the degree of carbamation expressed as $\% \mathrm{~N}$ and (c) the technique applied.

It is also obvious from the data that on using carbamate derivative of low $\% \mathrm{~N}$ the magnitude of the percent colour removal was 81.5 and $67.8 \%$ on using reactive violet5 and 75.5 and $58.8 \%$ on using reactive blue19 for the sample acquire the relatively higher $\% \mathrm{~N}$ it was 86.1 and $77.7 \%$ on using reactive blue 19 on using either ultrasonic or mechanical shaking, respectively.

It can be concluded that in all cases, i.e. irrespective of the nature of dyes used or the technique applied, the magnitude of the adsorbed colour depends on the $\%$ $\mathrm{N}$ whereas $\% \mathrm{~N}$ increases the $\%$ colour removal increases too. This is expected since amino group acquire positive charge and the reactive dye acquires negative charge.

\section{References}

1. Elwan, M. M., Attriss, M. S., Mahmoud, A. A. and Salem, A. S., Characterization of rice straw/ash and using in clay bricks. Proceeding of First Scietific Environmental Conference (pp. 79 - 92). Zagazig University, Egypt (2006).

2. Hanafi, E. M., El-Khadrawy, H. H., Ahmed, W. M. and Zaabal, M. M., Some observations on rice straw with emphasis on updates of its management. World Applied Sciences Journal, 16(3), 354-361 (2012).

3. Bhise, R. M., Patil, A. A., Raskar, A. R., J., P. P. and Deshpande, D. P., Removal of colour of spent wash by activated charcoal adsorption and electrocoagulation. Research Journal of Recent Sciences, 1(6), 66-69 (2012).

4. Tarley, C. R. and Arruda, M. A., Biosorption of heavy metals using rice milling byproducts. Characterisation and application for removal of metals from aqueous effluents. Chemosphere, 54(7), 987-995 (2004).

5. Priya, R., Nithya, R., Anuradha, R. and Kamachi, T., Removal of colour from crystal violet dye using low cost adsorbents. International Journal of ChemTech. Research, 6(9), 43-46 (2014).

6. Velmurugan, P., Rathina kumar, V. and Dhinakaran, G., Dye removal from aqueous solution using low cost adsorbent. International Journal of Environmental Sciences, 1(7) (2011).

7. Geethakarthi, A. and Phanikumar, B. R., Industrial sludge based adsorbents / industrial by-products in the removal of reactive dyes-a review. International Journal of Water Resources and Environmental Engineering, 2(3), 1-9 (2011).

8. Bouberka, Z., Kacha, S., Kameche, M., Elmaleh, S. and Derriche, Z., Sorption study of an acid dye from an aqueous solutions using modified clays. Journal of Hazardous Materials, 119(1-3), 117-124 (2005). 
9. Taha, D. N., Samaka, I. S. and Khalil, A. H., Comparative adsorption study for the basic dye wastewater treatment using natural iraqi clay minerals and various adsorbents. J. Education College - University of Babylon - Iraq, 2(2), 229-246 (2009).

10. Janos, P., Sorption of basic dyes onto iron humate. Environ. Sci. Technol. 37(24), $5792-5798$ (2003).

11. Banat, I. M., Nigam, P., Singh, D. and Marchant, R., Microbial decolorization of textile-dyecontaining effluents: A review. Bioresource Technology, 58(3), 217-227 (1996).

12. Ponnusami, V., Vikram, S. and Srivastava, S. N., Guava (Psidium guajava) leaf powder: Novel adsorbent for removal of methylene blue from aqueous solutions. Journal of Hazardous Materials, 152(1), 276-286 (2008).

13. Sun, G. and Xu, X., Sunflower stalks as adsorbents for color removal from textile wastewater. Industrial \& Engineering Chemistry Research, 36(3), 808-812 (1997).

14. Abd El-Thalouth, I., El-Hennawi, H. M., Abd El-Salam, S. S. and Adel, E., Minimization of dyestuff pollutions using native, alkali-treated or bleached cellulose of rice straw as adsorbent. Indian Journal of Fibre and Textile Research, 38, 144-149 (2013).

15. Hassabo, A. G., Mendrek, A., Popescu, C., Keul, H. and Möller, M., Deposition of functionalized polyethylenimine-dye onto cotton and wool fibres. Research Journal of Textile and Apparel, 18(1), 36-49 (2014).

16. Vogel, A. I., Elementary Practical Organic Chemistry, Part (3), "Quantitive Organic Analysis". London: Longman Group Ltd (1957).

(Received 25/8/2015; accepted 19/10/2015) 


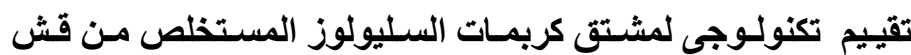

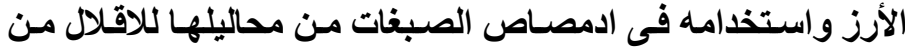 التلوث}

ابراهيم عبد الثالوث ، هبـه محمل الحنــاوي ، سـميه توفيق" ، شـريف عبد السـلام”

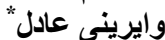
شعبة الصناعات النسجيه ــ المركز القو مى للبحوث و "كليـة الفنون التطبيقيه - جامعة

فى هذا البحث تم تحضير اللب السليولوزى من فش الأرز عن طريق الغليان فى في

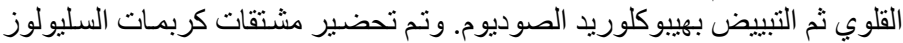

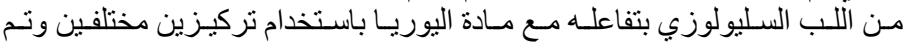

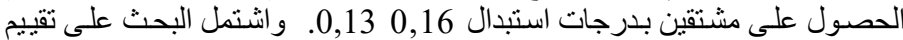

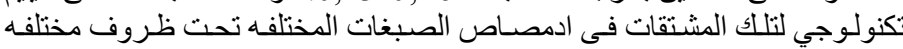

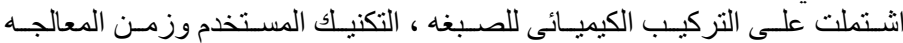

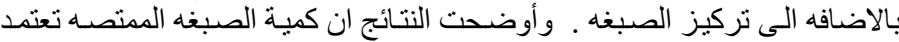

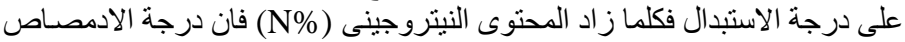

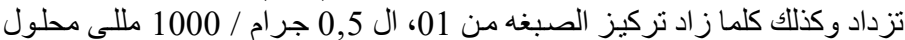

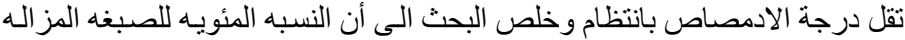

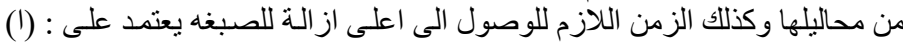

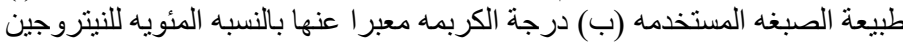

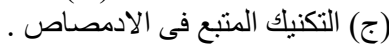

